\title{
Ileovesicostomy for Adults With Neurogenic Bladders: Complications and Potential Risk Factors for Adverse Outcomes
}

\author{
Hung-Jui Tan, ${ }^{1}$ John Stoffel, ${ }^{2}$ Stephanie Daignault, ${ }^{1}$ Edward J. McGuire, ${ }^{1}$ and Jerilyn M. Latini ${ }^{1 *}$ \\ ${ }^{1}$ Department of Urology, University of Michigan, Ann Arbor, Michigan \\ ${ }^{2}$ Department of Urology, Lahey Clinic, Lexington, Massachusetts
}

\begin{abstract}
Aims: Risk factors for complications following ileovesicostomy have not been well defined. This study's purpose was to examine outcomes following ileovesicostomy in adults and identify possible risk factors that may contribute to postoperative complications. Methods: Retrospective database review identified ileovesicostomy procedures from August 1999 to September 2003. Demographic, pre-operative, and post-operative data were extracted. Statistical analysis determined whether risk factors influenced outcomes of urethral continence, re-operation, and post-operative complications. Factors included age, tobacco use, diabetes, neurogenic bladder etiology, body mass index, pre-operative indwelling catheterization, or simultaneous procedures including pubovaginal sling/urethral closure. Results: 50 adults status-post ileovesicostomy were identified. At last follow-up, 36 patients (72\%) were continent per urethra. The incidence of complications decreased significantly from 3.38 per patient to 1.16 post-operatively $(P<0.0001)$. Twenty-seven averaged 1.52 inflammatory or infectious post-operative complications per patient, 19 averaged 1.47 stomal complications, and 11 averaged 2.09 ileovesicostomy mechanical obstructions. Overall, 27 required 2.85 reoperations or additional procedures following ileovesicostomy. Sub-group analysis identified BMI $(P=0.0569)$ as a possible risk factor. Differences in outcomes based on age, tobacco use, diabetes, neurogenic bladder etiology, preoperative indwelling catheterization, or urethral closure were not significant. Conclusions: Ileovesicostomy is a valuable management option for adults with neurogenic bladder unable to perform intermittent catheterization. The incidence of urinary tract comorbid events significantly decreased following ileovesicostomy though the onset of other complications should be considered. The morbidity associated with ileovesicostomy requires careful patient selection, close long-term follow-up, and potential subsequent interventions to address post-operative complications. Neurourol. Urodynam. 27:238-243, 2008. (c) 2008 Wiley-Liss, Inc.
\end{abstract}

Key words: complications; ileovesicostomy; neurogenic bladder; obesity; pubovaginal sling; urethral closure

\section{INTRODUCTION}

Clean intermittent catheterization (CIC) is an efficacious and safe modality for bladder management in adults with neurogenic bladder. ${ }^{1}$ However, severe limitations in dexterity or cognitive abilities, poor ancillary care, urethral deterioration (functional incompetence, erosion, etc.) or absence of patient motivation may prevent successful implementation and compliance with CIC. Alternatives include sphincterotomy, urinary diversion, and urinary reconstruction. Unfortunately, most patients are often relegated to chronic indwelling urinary catheterization, which can be associated with many complications and has limited effectiveness in maintaining a low-pressure system. ${ }^{2}$

Alternatives that require catheterization such as continent ileovesicostomy, bladder augmentation, and urinary diversion with neobladder or pouch may be subject to similar limitations that prevent patients from utilizing CIC. Two common alternatives to the incontinent ileovesicostomy include ureteroileostomy (ileal conduit) or sphincterotomy with external condom catheter. Sphincterotomy with external condom catheter has been utilized to decrease outlet obstruction and intravesical pressures; however, it is only viable in men, and failure rates have been reported to be as high at $30 \%$ due to appliance difficulties or persistent elevation in urinary tract pressure. ${ }^{3,4}$ Supravesical urinary diversions require more extensive dissection of the ureters and ureterointestinal anastomosis, resulting in the loss of the native vesicoureteral junction. Previous series in patients with neurogenic bladder report good renal function but high rates of long-term complications that includes pyocystis, pyelonephritis, bowel complications, metabolic derangements, and complication of the ureterointestinal anastomosis. ${ }^{5-8}$ Stomal complication rates as high as $31 \%$ and upper tract dilation and/or deterioration from $27 \%$ to $34 \%$ have been reported. ${ }^{7,8}$

Ileovesicostomy has been shown to be a valuable alternative for adults with neurogenic bladder who are incapable or otherwise not willing to perform CIC. Several studies have shown that the procedure can achieve urethral continence, reduce bladder storage pressures, and offer a reliable, low maintenance method for urine evacuation. ${ }^{9-13}$ However, factors that may worsen outcomes have not been well studied. In general, both obesity and indwelling catheters have shown considerable morbidity to the neurogenic bladder population..$^{1,2,14,15}$ Tobacco use, diabetes, and age have been identified as possible risk factors for incontinence, tissue and wound complications, anastomotic leakage, or lower urinary tract symptoms. ${ }^{16-19}$ Neurologic lesion, concurrent surgical procedures, and re-operation are also possible factors that may influence outcomes following ileovesicostomy surgery. The

No conflict of interest reported by the author(s)

Dirk De Ridder led the review process.

${ }^{*}$ Correspondence to: Jerilyn M. Latini, MD, Assistant Professor, Department of Urology, University of Michigan Health System, 1500 East Medical Center Drive, 3887 Taubman Health Care Center, Box 0330, Ann Arbor, MI 48109-0330.

E-mail: jerilati@med.umich.edu

Received 9 March 2007; Accepted 9 May 2007

Published online in Wiley InterScience

(www.interscience.wiley.com)

DOI 10.1002/nau.20467 
purpose of this study was to examine our series of patients who have had incontinent ileovesicostomy urinary diversion to determine long-term urethral continence rates, need for re-operation, number and type of complications, and to identify potential risk factors that may predict poor outcomes following ileovesicostomy surgery.

\section{MATERIALS AND METHODS}

\section{Patient Data}

Operative logs were reviewed from a single surgeon (EM) at our institution (University of Michigan) between August 1999 and September 2003 for patients who underwent incontinent ileovesicostomy urinary diversion. An IRB approved retrospective chart review was conducted. Demographic data extracted included history of tobacco use, diabetes, age and body mass index (BMI; $\mathrm{kg} / \mathrm{m}^{2}$ ) at time of surgery, etiology of neurogenic bladder, method and duration of preoperative bladder drainage, and additional or concurrent procedures. National Institute of Health definitions were used to categorize weight status. Laboratory studies were reviewed for culture positive urinary tract and hematologic infections and correlated with outpatient and inpatient documentation to determine clinical significance. Reports from all radiological studies were reviewed and any abnormalities were recorded.

Indications for surgery included neurogenic bladder in patients incapable of CIC, incontinence refractory to conservative medical bladder management, elevated detrusor leak point pressures, low bladder compliance, detrusor sphincter dyssynergia, hydronephrosis, vesicoureteral reflux, and decreased renal function. All patients had been assessed with physical exam and fluoroscopic urodynamic studies (FUDS) pre-operatively and at 3 and 6 months post-ileovesicostomy. FUDS were performed with patients in the supine or upright position at a moderate fill rate $(50 \mathrm{ml} / \mathrm{min})$ until detrusor overactivity occurred or bladder volumes reached storage capacity. Bladder compliance and detrusor leak point pressures were measured, and a concomitant fluoroscopic voiding cystourethrogram was performed. FUDS were reviewed for vesicoureteral reflux, low bladder compliance, detrusor sphincter dyssynergia (DSD), and ileovesicostomy obstruction post-operatively. Low bladder compliance was defined as $<20 \mathrm{ml} / \mathrm{cm} \mathrm{H}_{2} \mathrm{O}$ change on cystometrogram (CMG) Ileovesicostomy was considered obstructed if the detrusor leak point pressure per stoma or urethra was greater than $40 \mathrm{~cm} \mathrm{H} \mathrm{H}_{2} \mathrm{O}$ and no contrast could be visualized effluxing from the stoma fluoroscopically. Continence was defined as no leakage per urethra after stress maneuvers on FUDS or physical exam.

Outcome measures after ileovesicostomy surgery examined in this study included change in urethral continence, change in number of urinary tract co-morbidities, and number of post-operative surgical complications. Persistent or recurrent urethral incontinence was defined as leakage per urethra during FUDS or as subjective patient complaints of leakage or greater than 1 pad per day as recorded during each follow-up appointment. Pre-operative lower and upper urinary tract comorbidities were identified through patient history or patient encounter notes. Any adverse event diagnosed during follow-up appointments or requiring additional treatment were defined as new complications such as post-op ileus, conduit obstruction, urosepsis, or bladder/renal calculi. Stomal complications were defined as clinically significant stomal prolapse, stenosis, retraction, herniation, skin break down, or appliance issues that required additional treatment beyond routine stomal care. Clinical, urodynamic, or radiological evidence of low bladder compliance, ileovesicostomy obstruction, urosepsis, urinary tract calculi, hydronephrosis, ureteral reflux, autonomic dysreflexia, and urinary tract fistulas that were new-onset post-operatively were considered complications. Infectious or inflammatory events that influenced surgical wound healing or bowel function was also considered complications. Finally, occurrences of re-operation or additional post-operative procedures were recorded. Preexisting conditions (comorbid urinary conditions including incontinence) that persisted despite ileovesicostomy and concomitant treatment, that is, persistent urethral fistula, were not counted as new complications.

\section{Ileovesicostomy Operative Technique}

All patients were admitted 2 days prior to surgery for mechanical and antibiotic bowel preparation and stoma site marking by an enterostomal specialist. Ileovesicostomy was performed under general anesthesia in the manner described by Schwartz et al. ${ }^{9}$ All patients were drained for 3-4 weeks after surgery with a 22 Fr catheter per stoma. The Foley catheter was removed approximately 3-4 weeks post-operatively once adequate drainage from the ileovesicostomy and no post-operative urinary extravasation were verified on FUDS. Other procedures that were commonly performed concomitantly with ileovesicostomy were augmentation enterocystoplasty, urethral closure, suprapubic sinus closure, pubovaginal or perineal sling, and/or urinary fistula repair.

Following catheter removal, patients were followed clinically with repeat FUDS as described above. After 6 months following ileovesicostomy, if patients developed new or recurrent incontinence, symptomatic urinary infections, difficulty with urine drainage, changes in renal function or radiographic imaging such as renal ultrasound, etc. then repeat video fluorourodynamics often with cystoscopy were performed. Additionally, cystoscopy (either via the native urethra or the ileovesicostomy stoma) beginning at 3-5 years after ileovesicostomy to monitor for calculi and cancer surveillance, given the long-term risk for secondary malignancy.

\section{Statistical Analysis}

Ordinal categorical variables such as number of complications were tested using Cochran-Mantzel-Hanzel tests. Fisher's Exact tests were used for nominal categorical comparisons. Spearman Correlation was used to examine correlation between continuous variables total complications and stomal complications. Statistical analysis was performed using SAS 9.1 software (SAS Institute, Cary, NC) with 5\% significance used in all tests and comparisons.

\section{RESULTS}

Fifty patients, 21 men and 29 women, were identified. Forty-four (88\%) patients were incontinent despite conservative bladder management. Thirty-seven patients (79\%) were managed with an indwelling urethral and/or suprapubic catheter prior to ileovesicostomy for a median 30 months (range 1-312) before surgery. Pre-operative neurogenic bladder management is listed in Table I. Mean patient age at time of ileovesicostomy was 45 years (range 20-79). Mean followup after surgery was 26.3 months (range 1-79). Mean preoperative serum creatinine was $0.8 \mathrm{mg} / \mathrm{dL}$ (range $0.3-5$ ). The median BMI for our patient sample was $23.9 \mathrm{~kg} / \mathrm{m} 2$ (range 15.6-50.4). Three patients were excluded from analysis 
TABLE I. Patient Characteristics

\begin{tabular}{|c|c|}
\hline Characteristic & No. (\%) \\
\hline Number of patients & 50 \\
\hline Mean age at surgery (years) & $45(20-79)$ \\
\hline Mean follow-up (years) & 26.3 months (1-79) \\
\hline \multicolumn{2}{|l|}{ Gender } \\
\hline Female & $29(58 \%)$ \\
\hline Male & $21(42 \%)$ \\
\hline \multicolumn{2}{|l|}{ Age } \\
\hline$\leq 50$ years & $29(58 \%)$ \\
\hline$>50$ years & $21(42 \%)$ \\
\hline \multicolumn{2}{|l|}{ Neurologic lesion } \\
\hline Spinal cord injury & $21(42 \%)$ \\
\hline Multiple sclerosis & $19(38 \%)$ \\
\hline Spina bifida & $3(6 \%)$ \\
\hline $\begin{array}{l}\text { Radical retropubic prostatec- } \\
\text { tomy }\end{array}$ & $2(4 \%)$ \\
\hline Cerebral dysfunction & $1(2 \%)$ \\
\hline Spinal stenosis & $1(2 \%)$ \\
\hline Non-Hodgkin's lymphoma & $1(2 \%)$ \\
\hline \multicolumn{2}{|l|}{ Concurrent procedures } \\
\hline Pubovaginal sling & $19(65.5 \%)$ \\
\hline Urethral closure & $10(20 \%)$ \\
\hline Suprapubic closure & $10(20 \%)$ \\
\hline Enterocystoplasty & $6(12 \%)$ \\
\hline Urinary fistula repair & $3(6 \%)$ \\
\hline \multicolumn{2}{|l|}{ Co-morbidities } \\
\hline $\begin{array}{l}\text { Indwelling catheter (urethral } \\
\text { or suprapubic) }\end{array}$ & 37 (74\%) \\
\hline Median catheter duration & 30 months (1-312) \\
\hline Tobacco use & $17(34 \%)$ \\
\hline Diabetes & $6(12 \%)$ \\
\hline \multicolumn{2}{|l|}{ BMI $\left(\mathrm{kg} / \mathrm{m}^{2}\right)$} \\
\hline$<20$ & $5(11.1 \%)$ \\
\hline $20-25$ & $19(42.2 \%)$ \\
\hline $25-30$ & $11(24.2 \%)$ \\
\hline$>30$ & $10(22.2 \%)$ \\
\hline
\end{tabular}

involving BMI due to amputation. The most common causes of neurogenic bladder were spinal cord injury in 21 patients and multiple sclerosis in 19 patients. Of 27 patients with formal classification of their level of neurologic disease, 15 were classified with quadriplegia and 12 with paraplegia. Concomitant procedures include 19 sling procedures, 10 urethral closures, and 10 suprapubic closures. Remaining demographic data is included in Table I.

After ileovesicostomy, 36 (72\%) patients were continent at last follow-up. Post-operatively, mean serum creatinine was $0.7 \mathrm{mg} / \mathrm{dL}$ (range 0.3-1.4). In the four patients with preoperative hydronephrosis, the hydronephrosis resolved in all 4 and there was no development of new hydronephrosis noted in our series. There were no deaths within the first 12 months post-operatively. Four patients later died from disease unrelated to ileovesicostomy while another expired from an unknown cause. One patient with a history of C6 tetraplegia, urosepsis, and acute renal failure died from presumed urosepsis. He underwent ileovesicostomy, and at his last urology follow-up 17 months postoperatively, he had a well-functioning diversion without any complications. Review of records reveals multiple admissions for pseudomonas pneumonia following his last urology follow-up. His most recent admission was for sepsis, fungemia, and acute renal failure secondary to hydronephrosis due to bilateral obstructing ureteral stones, which improved following antimicrobial therapy and bilateral percutaneous nephrostomy tube placement. Prior to discharge, he went into respiratory arrest and expired.
Pre-operatively, all patients had at least 1 lower or upper urinary tract comorbidity secondary to their urologic condition (total 169). Overall, 47 patients (94\%) had at least one complication involving the urinary tract prior to ileovesicostomy surgery. Post-operatively, comorbid conditions affecting the urinary tract decreased significantly, from 3.38 per patient to 1.16 post-operatively $(P<0.0001)$ with a total of 57 complications in 37 patients (74\%). Urinary tract infections (UTIs) were recorded in 34 patients pre-operatively, but postoperative UTIs were not included in the analysis due to unreliable diagnoses secondary from colonization of the ileovesicostomy. The incidence of each type of lower or upper urinary tract condition decreased post-operatively except urinary fistula and hematuria (Table II).

There were 28 stomal complications occurring in 19 patients $(38 \%)$ with the most common being difficulties with stomal appliance (14 patients) and stomal stenosis (8 patients) (Table III). Mechanical difficulties with the ileovesicostomy conduit were identified utilizing FUDS and physical examination. Overall, 23 obstructions of the ileovesicostomy diversion in a total of 11 patients (22\%) were identified, including fascial stenosis, ileovesicostomy kinking due to redundancy, ileovesicostomy stricture, and mucus plugging (Table III). Wound or bowel complications related to infectious or inflammatory events immediately following the procedure included 17 wound infections, 13 small bowel obstructions or post-operative ileus, 5 wound dehiscence, and 4 patients had an intra-abdominal abscess or peritonitis. Twenty-seven patients required 77 procedures including 6 ileovesicostomy revisions, 9 stoma revisions, 9 sling procedures, and 7 urethral closures (Table IV). Among patients undergoing re-operation, 11 patients had 33 fistula closures though 4 had a previous history of fistulas. The frequency of re-operation differed significantly based on number of total complications $(P<0.0001)$ and stomal complications $(P=0.0417)$. All 16 patients with 4 or more complications required a re-operation whereas $35.5 \%$ of patients with $1-$ 3 complications required re-operation. Of 19 patients with stomal complications, $73.7 \%$ required re-operation whether for stomal or other complications compared to $41.9 \%$ of patients without stomal complications.

No statistically significant difference was found in total complications between those with concurrent pubovaginal sling surgery and those without $(P=0.20)$. There was no significant difference for total complications $(P=0.1617)$, stomal complications $(P=0.3516)$, need for re-operation $(P=0.3079)$, or incontinence $(P=0.3563)$ was found among patients undergoing a urethral closure (Table V).

TABLE II. Comorbid Conditions of the Urinary Tract

\begin{tabular}{lcc}
\hline Complication & $\begin{array}{c}\text { Pre-operative } \\
\text { No. (\%) }\end{array}$ & $\begin{array}{c}\text { Post-operative } \\
\text { No. (\%) }\end{array}$ \\
\hline Urinary tract infection & $34(68)$ & NR \\
Urethral erosion/stricture & $27(54)$ & NR \\
Urosepsis & $12(24)$ & $4(8)$ \\
Urinary fistula & $10(20)$ & $16(32)$ \\
Renal calculi & $7(14)$ & $1(2)$ \\
Dysreflexia (autonomic) & $7(14)$ & $3(6)$ \\
Vesicoureteral reflux & $6(12)$ & $3(6)$ \\
Bladder calculi & $4(8)$ & $3(6)$ \\
Hematuria & $4(8)$ & $9(18)$ \\
Hydronephrosis & $4(8)$ & $0(0)$ \\
Pyelonephritis & $4(8)$ & $1(2)$ \\
Bladder neoplasia & $0(0)$ & $0(0)$ \\
\hline
\end{tabular}


TABLE III. Complications

\begin{tabular}{|c|c|c|}
\hline Category & Complication & $\begin{array}{l}\text { Number of } \\
\text { patients (\%) }\end{array}$ \\
\hline \multirow[t]{7}{*}{ Stomal } & All & $19(38)$ \\
\hline & Appliance & $14(28)$ \\
\hline & Stenosis & $8(16)$ \\
\hline & Ulceration & $3(6)$ \\
\hline & Retraction & $2(4)$ \\
\hline & Hernia & $1(2)$ \\
\hline & Prolapse & $0(0)$ \\
\hline \multirow[t]{6}{*}{ Mechanical complication } & All & $11(22)$ \\
\hline & Ileovesicostomy obstruction & $6(12)$ \\
\hline & Fascial stenosis & $6(12)$ \\
\hline & Kink & $5(10)$ \\
\hline & Mucous plug & $4(8)$ \\
\hline & Stricture & $2(4)$ \\
\hline \multirow{6}{*}{$\begin{array}{l}\text { Wound/bowel } \\
\text { complications }\end{array}$} & All & $27(54)$ \\
\hline & Wound infection & $17(34)$ \\
\hline & Small bowel obstruction/ileus & $13(26)$ \\
\hline & Wound dehiscence/evisceration & $5(10)$ \\
\hline & Intra-abdominal abcess/peritonitis & $4(8)$ \\
\hline & Incisional hernia & $2(4)$ \\
\hline
\end{tabular}

No statistically significant difference in urethral incontinence and stomal complications between patients with BMI $\leq 25$ and patients with BMI $>25$ was found; however, a trend toward significance was found for total complications between these two groups. Among 21 patients with BMI $>25,52.4 \%$ had 4 or more complications and $42.9 \%$ had 1-3 complications whereas $20.8 \%$ of 24 patients with BM$\leq 25(P=0.0569)$ had 4 or more complications and $75 \%$ had $1-$ 3 complications (Table V). For re-operation, $66.7 \%$ of patients with BMI $>25$ required a re-operation compared to $41.67 \%$ of patients with $\mathrm{BMI} \leq 25(P=0.1363)$.

No statistical difference was found between patients with indwelling catheter use before ileovesicostomy and those without in terms of total complications $(P=0.8885)$, stomal complications $(P=1.000)$, re-operation $(P=0.563)$, or incontinence $(P=0.4382)$. Additionally, patients with diabetes, current tobacco use, multiple sclerosis, and age $<50$ at time of surgery were compared to patients without diabetes, current tobacco use, spinal cord injury, and age $\geq 50$, respectively. No statistical significant difference was identified in terms of total complication number, stomal complications, need for re-operation, or urethral incontinence.

\section{DISCUSSION}

In adults with neurogenic bladder, CIC remains an efficacious modality for bladder management. ${ }^{20}$ In patients

TABLE IV. Re-operation Following Primary Surgery

\begin{tabular}{lcc}
\hline Procedures & No. patients & No. procedures \\
\hline Ileovesicostomy revision & 6 & 6 \\
Stoma revision & 8 & 9 \\
Urethral closure & 6 & 7 \\
Urinary fistula closure & 11 & 33 \\
Pubovaginal or perineal sling & 7 & 9 \\
Botox injection (bladder) & 4 & 11 \\
Collagen injection & 2 & 3 \\
Wound (incision) repair & 6 & 7 \\
Other & 1 & 1 \\
Total & 27 & 77 \\
\hline
\end{tabular}

TABLE V. Pubovaginal Sling and Obesity Versus Total Complications

\begin{tabular}{lcccc}
\hline & \multicolumn{3}{c}{ Complications } & \\
\cline { 2 - 4 } Pubovaginal sling & None & $1-3$ comps & 4+ comps & Total \\
\hline None & $1(12.5 \%)$ & $6(75.0 \%)$ & $1(12.5 \%)$ & 8 \\
Concurrent & $2(10.5 \%)$ & $10(52.6 \%)$ & $7(36.8 \%)$ & $19(65.5 \%)$ \\
Post & $0(0 \%)$ & $0(0 \%)$ & $2(100 \%)$ & $2(6.9 \%)$ \\
$\quad$ ileovesicostomy & & & & \\
Obesity & & & & \\
$\quad \leq 25$ & $1(4.2 \%)$ & $18(75 \%)$ & $5(20.8 \%)$ & 24 \\
$\quad 25$ & $1(4.7 \%)$ & $9(42.9 \%)$ & $11(52.4 \%)$ & 21 \\
\hline
\end{tabular}

unable to perform $\mathrm{CIC}$, incontinent ileovesicostomy is a viable alternative, shown to resolve urethral incontinence, maintain a low pressure system, and reduce urinary tract dysfunction..$^{9-13,21-23}$ Our study is the largest series to date and the first to examine potential risk factors that may affect the incidence of persistent urethral incontinence, stomal complications, re-operation, or total complications after ileovesicostomy surgery. We found ileovesicostomy to be a valuable procedure though associated with significant comorbidities and complications that requires diligent followup. Utilization of urethral closure as oppose to a sling procedure and careful consideration of body habitus may decrease the incidence of poor outcomes.

Prior to this publication, Leng et al. ${ }^{11}$ provided the most detailed assessment of pre- and post-operative comorbidities. Our higher overall complication rate while maintaining the same primary surgeon may reflect our stringent criteria for complications and the utilization of computer-based documentation. Although our complication rate is higher pre-operative comorbid conditions of the lower and upper urinary tract decreased significantly following ileovesicostomy surgery similar to Leng et al. ${ }^{11}$ Only 1 patient had a complication involving the upper tract (renal stones) of which he had a prior history, and no patients had hydronephrosis or renal failure post-operatively, supporting the effectiveness of ileovesicostomy surgery to create a low-pressure system. While CIC remains the ideal management, ileovesicostomy offers similar reduction in complications of the urinary tract compared to indwelling catheterization.

At last follow-up, $72 \%$ of our patients achieved urethral continence compared to rates of $67-100 \%$ reported by previous series. ${ }^{9,10,12,13,21-23}$ Within the first 6 months, $42 \%$ achieved urethral continence while 13 of 29 (44.8\%) at 1-year follow-up were dry. Continence rates subsequently increased as 22 of 32 patients with follow-up greater than 1 year were found to be dry. A large portion of our series required reoperation to address persistent urethral incontinence. Of 27 patients requiring re-operation, 25 were incontinent at some point post-operatively with 13 achieving continence at last follow-up. In contrast, 20 of 23 patients not requiring reoperation were dry at last follow-up. This suggests that urethral continence improves with time, requiring diligent follow-up to troubleshoot problems that may arise and augment therapy with either medication or additional surgery.

While untoward events related to the urinary tract are reduced significantly, a large portion of patients experience complications of the stoma and ileovesicostomy conduit. Most concerning was the increased incidence of ileovesicostomy obstruction requiring treatment, occurring in $22 \%$ of our series compared to $0-14 \%$ in previous series. Our rate may be 
elevated partially due to the inclusion of mucous plugging and ileal kink, which are often managed easily with irrigation and/or catheterization of the ileovesicostomy, respectively. Similarly, our stoma complication rate appears to be elevated in part due to the inclusion of appliance difficulties that were addressed in clinic non-operatively. Excluding difficulties with appliance, 11 patients had 14 stomal complications, which is comparable to existing literature. Factors that prevent patients from effectively utilizing CIC may also impair their ability to ideally manage their stomal appliance, resulting in additional minor complications. Though easily manageable, minor complications should not be discarded. Both physicians and patients should be aware of the trade-off between reduction in urinary dysfunction and possible development of post-operative complications, both major and minor, when considering ileovesicostomy surgery.

Various risk factors for incontinence, poor wound healing, and lower urinary tract symptoms have been identified in the literature. However, our analysis failed to show any relationship between age, tobacco use, or diabetes and our measured outcomes. The analysis failed to identify pre-existing catheter use as a risk factor for increased complications after ileovesicostomy. One limitation stems from the use of indwelling catheterization as a marker of GU trauma/morbidity. Future studies evaluating outcomes in terms of preoperative health of the GU system may reveal a relationship; however, larger numbers of patients and more clearly defined pre-operative criteria would be needed. While our series is the largest to date, our sample size may be too small to identify the influence of any individual risk factor, especially given the overall health status of these patients that may overshadow these risk factors.

Our sub-group analysis did show a trend toward significance in total complications based on BMI. However, the analysis did not show any significant difference in incontinence or stomal complications based on BMI although several studies have identified obesity as a potential risk factor for these measured outcomes. Arumugam et al. ${ }^{24}$ and Leenen and Kuypers ${ }^{25}$ noted that high BMI was associated with worse stomal surgery outcomes. Interestingly, BMI may have limited utility in assessing this patient population. Several studies have shown that BMI underestimates adiposity among patients with spinal cord injury, ${ }^{26}$ which may affect our analysis given our patient population. More detailed pre-operative assessment and better measurement of adiposity like abdominal girth or body fat percentage are needed to evaluate this relationship more conclusively.

Selection of concurrent anti-incontinence procedure was based primarily on clinical judgment. Although not specifically examined, patients with more extensive urethral erosion, especially if secondary to indwelling urethral catheterization, were likely to receive a urethral closure. Pubovaginal or perineal slings were generally performed in patients with partial erosions or poor urethral function. Interestingly, patients with concurrent pubovaginal or perineal sling had significantly more complications in the post-operative period. Despite the concern for fistula creation with urethral closure, our analysis showed no significant difference in urethral incontinence or post-operative complications in patients with both urethral closure and ileovesicostomy. Stoffel and McGuire ${ }^{27}$ previously reported the University of Michigan experience with concurrent ileovesicostomy and urethral closure and found that all patients were continent at last follow-up. However, they noted a high initial failure rate and the need for multiple re-operations to achieve urethral continence. While slings may be used to address a stress component or to provide a "functional" closure, urethral closure may be a better alternative than attempting a reconstruction of an eroded or weakened urethra. Despite this potential benefit, Stoffel and McGuire commented on concerns of durability, which is consistent with our experience as 4 of 15 patients receiving a urethral closure were incontinent per urethra at last follow-up.

CIC remains our first-choice method of management for adults with neurogenic bladder, however, a significant portion of this population lacks the dexterity, motivation, or support necessary for effective CIC. Prior to more invasive therapy, we encourage optimization of CIC through improved patient support and rehabilitation. Other treatment modalities such as newer anticholinergic agents and intravesical therapy with botulinum-A toxin should be considered prior to consideration of surgery. In patients refractory to conservative bladder management otherwise facing long-term indwelling catheterization, incontinent ileovesicostomy should be considered.

In our experience, for patients utilizing indwelling catheterization, early surgical intervention appears to be preferable to maximize health of the pelvic tissues and minimize complications of the urinary tract. We recommend the use of bladder neck closure as oppose to pubovaginal sling, which combined with earlier intervention and improved tissue health may improve urethral continence rates and decrease the occurrence of urethral fistulas. We recommend maximization of nutritional status and consideration of body habitus in treatment selection and technical construction of the stoma and conduit. Following ileovesicostomy, patients require diligent short-term and long-term follow-up to identify and address complications. Long-term follow-up should continue every 6-12 months.

While our complication rates are greater than previous series, they remain comparable to rates seen with ileal conduits. ${ }^{5-8}$ However, risk of upper tract deterioration and elevated urinary pressures appears to be less with incontinent ileovesicostomy. More recent series of incontinence urinary diversion have reported improved outcomes. Chartier-Kastler et al. ${ }^{28}$ recently reported their experience with 33 patients with spinal cord injury and noted resolution of incontinence in all patients with no metabolic derangements, $18 \%$ stomal complication rate, and $36 \%$ overall early and late complication rates.

Limitations of this study include the retrospective nature of the review. A prospective study with incontinence symptom surveys and pad weight testing pre-operatively and at rigorously scheduled intervals post-operatively would provide more information on patient satisfaction, quality of life, and the overall efficacy of the procedure. Our analysis fails to capture patients who may improve but not gain complete urethral continence. The sub-group analysis to identify potential risk factors was limited by the number of patients included in the series. While our experience is the largest to date, a larger population may better define pre-operative factors that may influence outcomes. Finally, the patient population and co-morbidities prevalent in this group complicate the analysis. Weakness in pelvic floor muscles and poor tissue quality likely increases complications and worsens incontinence; however, it is difficult to provide an objective measure of pelvic tissue health. Obesity may not be the most appropriate measure compared to abdominal girth or body fat percentage given the body composition of patients with spinal cord injury. Furthermore, the complicated nature of these patients demonstrated by the use of various types of additional procedures limits the ability to compare these procedures in terms of outcomes. 


\section{CONCLUSIONS}

Ileovesicostomy is a valuable long-term management strategy for adults with neurogenic bladder incapable of CIC. Based on our experience, ileovesicostomy provides an effective low-pressure conduit for urinary drainage, lowers detrusor leak point pressures, preserve upper urinary tract function, improves urethral continence, and decreases comorbid conditions affecting the urinary tract. Patients require careful selection, diligent post-operative follow-up, and continued urologic management to maintain ileovesicostomy function and resolve complications. Additional prospective analyses are needed to compare outcomes among various surgical options for adults with neurogenic bladder to optimize the long-term care for this patient population.

\section{REFERENCES}

1. Weld KJ, Graney MJ, Dmochowski RR. Differences in bladder compliance with time and associations of bladder management with compliance in spinal cord injured patients. J Urol 2000;163:1228-33.

2. Larsen LD, Chamberlin DA, Khonsari F, et al. Retrospective analysis of urologic complications in male patients with spinal cord injury managed with and without indwelling urinary catheters. Urology 1997;50:418-22.

3. Lockhart JL, Vortsman B, Weinstein D, et al. Sphincterotomy failure in neurogenic bladder disease. J Urol 1986;135:86-9.

4. Vapnek JM, Couillard DR, Stone AR. Is sphincterotomy the best management of the spinal cord injured bladder? J Urol 1994;151:961-4.

5. Comarr A. Renal complications of the ileal conduit and cutaneous vesicostomy among patients with cord bladders. J Urol 1972;107:762-5.

6. Moeller B. Some observations of 31 spinal cord injury patients on whom the Bricker procedure was performed. Paraplegia 1977;15:230-7.

7. Singh G, Wilkinson JM, Thomas DG. Supravesical diversion for incontinence: A long-term follow-up. BJU Int 1997;79:348-53.

8. Madersbacher S, Schmidt J, Eberle JM, et al. Long-term outcome of ilea conduit diversion. J Urol 2003;169:985-90.

9. Schwartz SL, Kennelly MJ, McGuire EJ, et al. Incontinent ileo-vesicostomy urinary diversion in the treatment of lower urinary tract dysfunction. J Urol 1994;152:99-102.

10. Chancellor MB, Erhard MJ, Kiilholma PJ, et al. Functional urethral closure with pubovaginal sling for destroyed female urethra after long-term urethral catheterization. Urology 1994;43:499-505.
11. Leng WW, Faerber G, Del Terzo $M$, et al. Long-term outcome of incontinent ileovesicostomy management of severe lower urinary tract dysfunction. J Urol 1999;161:1803-6.

12. Atan A, Konety BR, Nangia A, et al. Advantages and risks of ileovesicostomy for the management of neuropathic bladder. Urology 1999;54:636-40.

13. Gauthier AR, Winters JC. Incontinent ileovesicostomy in the management of neurogenic bladder dysfunction. Neurourol Urodyn 2003;22:142-6.

14. Korcina P. Body composition of spinal cord injured adults. Sports Med 1997;23:48-60

15. Spungen AM, Adkins RH, Stewart CA, et al. Factors influencing body composition in persons with spinal cord injury: A cross-sectional study. J Appl Physiol 2003;95:2398-407.

16. Daneshgari F, Moore C, Frinjari H, et al. Patient related risk factors for recurrent stress urinary incontinence surgery in women treated at a tertiary care center. J Urol 2006;176:1493-9.

17. Soresen LT, Hemmingsen U, Kallehave F, et al. Risk factors for tissue and wound complications in gastrointestinal surgery. Ann Surg 2005;241:654-8.

18. Sorensen LT, Jorgensen T, Kirkeby LT, et al. Smoking and alcohol abuse are major risk factors for anastomotic leakage in colorectal surgery. Br J Surg 1999:86:927-31.

19. Koskimaki J, Hakama M, Huhtala J, et al. Association of smoking with lower urinary tract symptoms. Scand J Urol Nephrol 2001;35:377-81.

20. McGuire EJ, Savastano J. Comparative urological outcome in women with spinal cord injury. J Urol 1986;135:730-1.

21. Rivas DA, Karasick S, Chancellor MB. Cutaneous ileocystostomy (a bladder chimney) for the treatment of severe neurogenic vesical dysfunction Paraplegia 1995;33:530-5.

22. Mutchnik SE, Hinson JL, Nickell KG, et al. Ileovesicostomy as an alternative form of bladder management in tetraplegic patients. Urology 1997;49:3537.

23. Gudziak MR, Tiguert R, Puri K, et al. Management of neurogenic bladder dysfunction with incontinent ileovesicostomy. Urology 1999;54:1008-11.

24. Arumugam PJ, Bevan L, MacDonald L et al. A prospective audit of stomasanalysis of risk factors and complications and their management. Colorectal Dis 2003;5:49-52

25. Leenen LP, Kuypers JH. Some factors influencing the outcome of stoma surgery. Dis Colon Rectum 1989;32:500-4

26. Jones LM, Legge $M$, Goulding A. Healthy body mass index values often underestimates body fat in men with spinal cord injury. Arch Phys Med Rehabil 2003;84:1068-71.

27. Stoffel JT, McGuire EJ. Outcome of urethral closure in patients with neurologic impairment and complete urethral destruction. Neurourol Urodyn 2006;25:19-22.

28. Chartier-Kastler EJ, Mozer P, Denys P, et al. Neurogenic bladder management and cutaneous non-continent ileal conduit. Spinal Cord 2002;40:443-8. 